\title{
Study of local Silica sand deposits for producing Leucite Glass-ceramics for dental applications
}

\author{
Siti Mazatul Azwa Saiyed Mohd Nurddin* and Malek Selamat \\ Mineral Research Centre, Department of Mineral and Geoscience Malaysia, Jalan Sultan Azlan Shah, Ipoh, Perak, Malaysia \\ *Corresponding Author: sazwa@jmg.gov.my (Siti Mazatul Azwa Saiyed Mohd. Nurddin)
}

\section{Article history :}

Received 4 February 2014

Revised 21 March 2014

Accepted 11 June 2014

Available online 18 August 2014

\section{GRAPHICAL ABSTRACT}

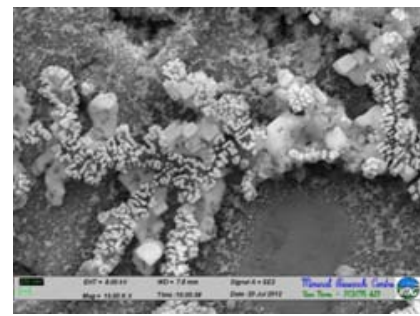

\section{ABSTRACT}

The objective of this research work was to examine the potential of using local silica sand from Terengganu, as a raw material in producing leucite glass-ceramics for dental applications. The characterization of the silica sand was carried out using chemical analysis and X-ray fluorescence (XRF) analysis. The study also focused on the effect of temperature and soaking time of sintering on the formation and properties of leucite glass-ceramics for dental applications. A starting glass composition of weight $\%$; $64.2 \% \mathrm{SiO}_{2}, 16.1 \% \mathrm{Al}_{2} \mathrm{O}_{3}, 13.6 \% \mathrm{~K}_{2} \mathrm{O}, 5.10 \% \mathrm{Na}_{2} \mathrm{O}, 0.5 \% \mathrm{TiO}_{2}$ and $0.5 \% \mathrm{LiO}_{2}$ was melted in an electric furnace, and then quenched in cool water to produce glass frit. The glass powders were ball milled and compressed to form $13 \mathrm{~mm}$ diameter discs. The discs were sintered at $700^{\circ} \mathrm{C}, 750^{\circ} \mathrm{C}, 800^{\circ} \mathrm{C}$ and $850^{\circ} \mathrm{C}$ for $1.0,3.0,6.0,9.0$ and 12.0 hours. The XRD analysis results show that the glass powders produced leucite phase as the major phase at certain temperature and soaking time of sintering. The sanidine (KAlSi $\mathrm{O}_{8}$ ) phase was also formed as the minor phase. The properties of sintered discs were studied using field emission scanning electron microscopy (FESEM), Vickers micro hardness and universal testing machine (UTM). Based on the microhardness and three point bending test results, the strength of the samples increased as the soaking time of sintering increased.

Keywords: Leucite, silica sand, sintering, crystallization

\section{INTRODUCTION}

Glass-ceramics have been successfully used for many years in dentistry to construct crowns and fixed partial bridges due to the properties of high mechanical strength, chemical inertness, wear resistance, aesthetics and low density. Presently, leucite, mica and lithium disilicate glassceramics are widely used as restorative materials [1].

Leucite is a potassium alumino-silicate $\left(\mathrm{KAlSi}_{2} \mathrm{O}_{6}\right)$ and represents a very promising material for dental applications. It was initially introduced into dental porcelain compositions to match the thermal expansion behaviour of the ceramic to that of the metal reinforcement when cooled. In addition, in last few years it was found that the presence of leucite also improves the composite strength and fracture toughness [2]. As the amount, average crystal size and structure of the leucite phase directly affect the thermal and mechanical properties of the final composite material; suitable technology of its preparation was necessary to be developed [3].

There are many methods in manufacturing leucite glass-ceramics. High expansion frits are blended with low expansion varieties, or synthetic leucites are similarly blended with glasses using fusion methods [4]. In recent years, another method of manufacturing of glass-ceramics has proven technically and commercially viable. This involves the sintering and controlling of crystallization of glass powders [5]. A powder processing route involves the melting, quenching, milling of glass frit, and sintering in order to promote crystallization, via nucleation and growth process.

In the formation of glass-ceramic systems used in dentistry that contains leucite as the main crystal phase, the crystallization of the base glass is difficult to control. Often, crystallization processes occur by uncontrolled surface nucleation mechanisms and crystals grow in different sizes and the residual microstucture is not uniform [6]. It is established, however, that alkali aluminosilicate glasses could be converted to glass-ceramics containing leucite, through controlled surface crystallization [7].

Current commercial manufacturing processes produce dental glass-ceramics with microstuctures consisting of larger $(5-10 \mu \mathrm{m})$ leucite crystals or clusters and volume fractions up to $45 \%$ leucite. A more controlled crystallization regime of the glass may therefore be a useful route to control the leucite crystal size, volume fraction and morphology of these materials, which can influence the mechanical glass-ceramic properties [8].

The aims of the research were to study the potential of using Terengganu silica sand as a raw material in producing leucite glass-ceramics as well as to examine the crystallization ability of the base glass sintered at various 
temperatures and periods in order to produce glass-ceramics that is suitable for restorative dental applications. In the present work we also investigated the flexural strength, microhardness and microstructure of glass-ceramics produced by powder sintering.

\section{EXPERIMENTAL}

\subsection{Glass and glass-ceramics synthesis}

A starting glass composition of weight $\% ; 64.2 \%$ $\mathrm{SiO}_{2}, 16.1 \% \mathrm{Al}_{2} \mathrm{O}_{3}, 13.6 \% \mathrm{~K}_{2} \mathrm{O}, 5.10 \% \mathrm{Na}_{2} \mathrm{O}, 0.5 \% \mathrm{TiO}_{2}$ and $0.5 \% \mathrm{LiO}_{2}$ was weighed. All oxides used were with purity in the range of 90 to $99 \%$ from Merck, Germany; Unilab, Australia and Hamburg Chemical except the $\mathrm{SiO}_{2}$ which is from Terengganu silica sand. The batches were placed in plastic bottles and mixed using a Heldoph Reax 2 Shaker, Germany for 12 hours in order to make sure the raw materials were homogenized. Zirconia balls were used as the media in the mixing process. Samples were melted in alumina crucibles in a bottom-loading high temperature furnace (Modutemp, Australia) at $10^{\circ} \mathrm{C} / \mathrm{min}$ to $1450^{\circ} \mathrm{C}$ and held for 3 hours, and then quenched in cool water to produce glass frit. The glass powders were milled (Retsch PM-400, Germany) for 1 hour and sieved to the required size of less than $75 \mu \mathrm{m}$. The glass powder was hand pressed using a laboratory hydraulic hand press (Carver, USA) in order to form $13 \mathrm{~mm}$ diameter and $2 \mathrm{~mm}$ thickness discs. The compacted discs were sintered in an electric furnace (Termo Temp, UK) at four different temperatures, which were $700^{\circ} \mathrm{C}, 750^{\circ} \mathrm{C}, 800^{\circ} \mathrm{C}$ and $850^{\circ} \mathrm{C}$. For each sintering temperature it was soaked for five different period: $1.0,3.0$, and 6.0, 9.0 and 12.0 hours. In these studies the experiments were carried out to explore the most favorable crystal growth temperatures and sintering times.

\subsection{Characterization of the glass-ceramics}

XRD (D8 Advanced, Bruker, Germany) was used for the identification of the crystalline phases in the glassceramics. Microstructure studies were done using field emission scanning electron microscopy (FESEM) (Supra 40 VP, Germany). Before viewing with FESEM, glassceramics specimens were embedded, polished and etched with $30 \%$ hydrofluoric acid for 7 seconds. The specimens were platinum coated and viewed using the secondary electron detector. The microhardness tests were carried out using a Matsuzawa, Model MMT-3, Japan. Glass-ceramics samples were embedded and polished in order to ensure that the tip of the indentation could be sharply focused and measured before the microhardness test was carried out. The flexural strength was measured using three point bending test with bars of $20 \mathrm{~mm} \times 5 \mathrm{~mm} \times 5 \mathrm{~mm}$ (Instron, UK, $0.5 \mathrm{~mm} / \mathrm{min}$ displacement).

Table 1 Chemical compositions of the silica sand

\begin{tabular}{|c|c|c|c|c|c|c|c|}
\hline Oxide & $\mathbf{S i O}_{2}$ & $\mathbf{A l}_{2} \mathbf{O}_{3}$ & $\mathbf{K}_{\mathbf{2}} \mathbf{O}$ & $\mathbf{N a}_{2} \mathbf{O}$ & $\mathbf{T i O}_{2}$ & $\mathbf{C a O}$ & $\mathbf{F e}_{2} \mathbf{O}_{3}$ \\
\hline Silica & 99.57 & 0.11 & 0.01 & 0.01 & 0.05 & 0.01 & 0.02 \\
\hline
\end{tabular}

\section{3. $\quad$ RESULTS \& DISCUSSION}

\subsection{Properties of the silica sand}

Chemical analysis results of the silica sand is presented in Table 1. The results reveal that the natural silica sand sample is highly pure and contain very low concentrations of impurities. The content of $\mathrm{Fe}_{2} \mathrm{O}_{3}$ is low. Generally, typical acceptable value of $\mathrm{Fe}_{2} \mathrm{O}_{3}$ in silicate glass product is between $0.02-0.03 \%$ (Malaysian Standard MS 701:1981).

\subsection{Phase Study by XRD method}

Generally, the XRD patterns of all samples showed phase changes with the increase of temperature and soaking time of sintering (Figure 1 and Figure 2(a), (b), (c) and (d)). The XRD patterns of the samples sintered at $700^{\circ} \mathrm{C}, 750^{\circ} \mathrm{C}$, $800^{\circ} \mathrm{C}$ and $850^{\circ} \mathrm{C}$ (Figure 1) and soaking time of 1 hour, indicated the presence of cubic leucite (ICDD:00-038-1423) as the major phase and sanidine as the minor phase. The peak intensity of the cubic leucite increased with temperature until $850^{\circ} \mathrm{C}$.

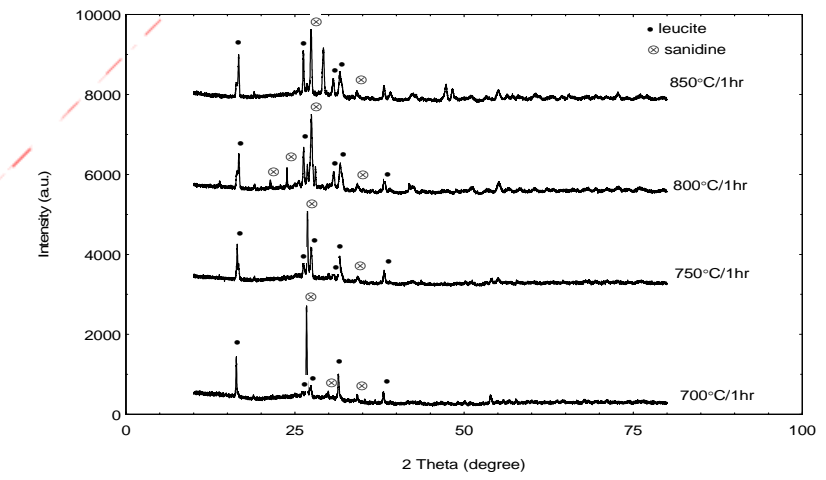

Fig. 1 The XRD patterns of the $700^{\circ} \mathrm{C}, 750^{\circ} \mathrm{C}, 800^{\circ} \mathrm{C}$ and $850^{\circ} \mathrm{C}$ samples sintered for 1 hour.

As the crystallization periods were further increased to 3, 6, 9 and 12 hours, all peaks associated with leucite become stronger as well as others coexistence phases which were sanidine (ICDD:00-019-1227 and microcline (ICDD:00-019-0932). For the sintering temperature at $700^{\circ} \mathrm{C}$ and $750^{\circ} \mathrm{C}$, the coexistence of sanidine, microcline and cubic leucite were observed when the sintering was held for 6 hours and further. Whereas for the $800^{\circ} \mathrm{C}$ and $850^{\circ} \mathrm{C}$ sintered glass, the sanidine, microcline and leucite started to form together when the sintering was held for 3 hours [9]. According to the $\mathrm{K}_{2} \mathrm{O}-\mathrm{Al}_{2} \mathrm{O}_{3}-\mathrm{SiO}_{2}$ ternary phase diagram this is due to the transformation of leucite and silica in the residual glass phase to sanidine as reported to occur in the temperature range of $800-950^{\circ} \mathrm{C}(\geq 60 \mathrm{~min}$ hold $)$ in leucite glass-ceramics. Several authors have also reported dramatic variations in crystal sizes in the same glass composition, depending on the crystallization heat treatment times and temperature [10] 
(a)

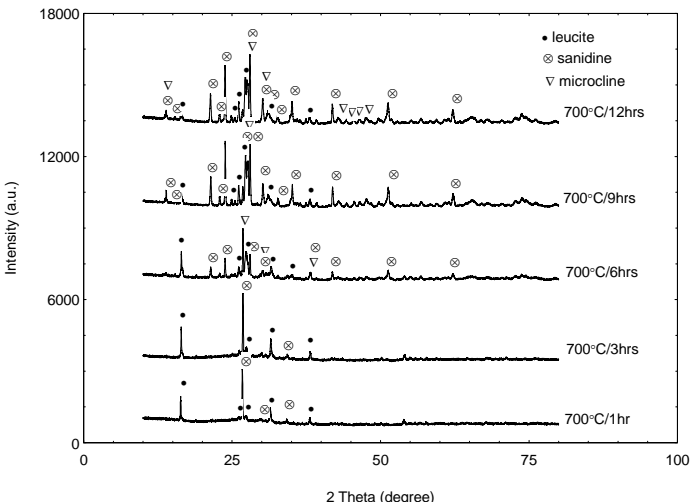

(b)

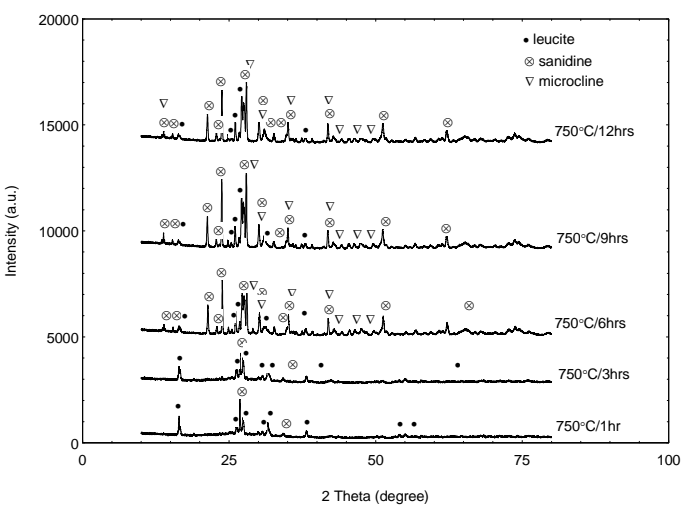

(c)

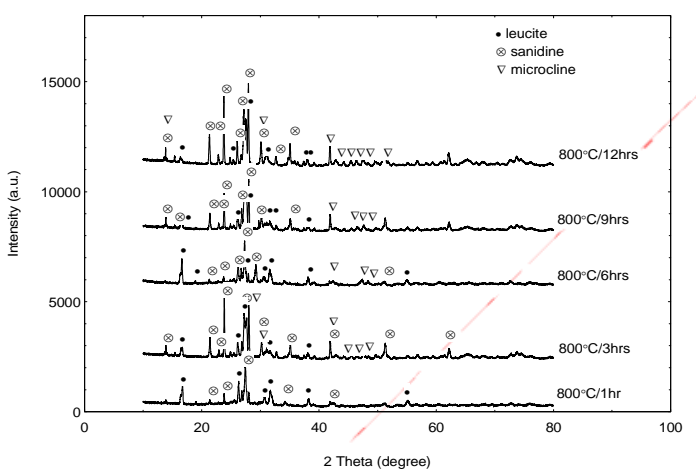

(d)

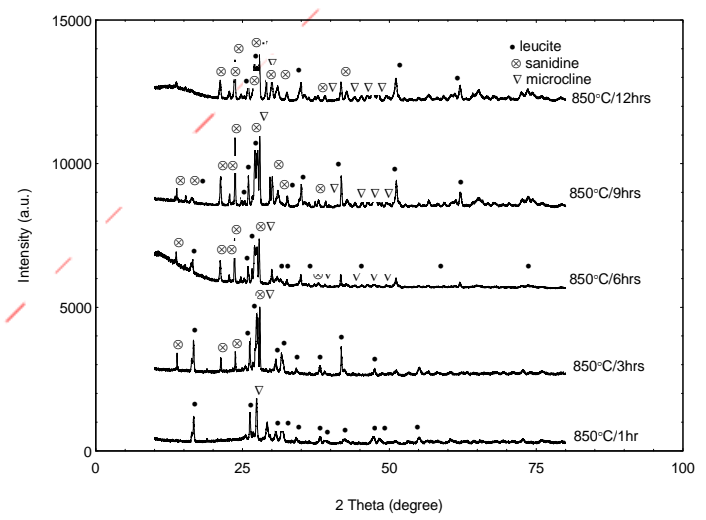

Fig. 2 The XRD patterns of samples sintered for 1.0, 3.0, 6.0, 9.0 and 12.0 hours (a)sintered at $700^{\circ} \mathrm{C}$; (b) $750^{\circ} \mathrm{C}$; (c) $800^{\circ} \mathrm{C}$; (d) $850^{\circ} \mathrm{C}$

\subsection{Three Point Bending Test and Vickers Microhardness}

Figure 3 and Figure 4 showed the graphs of the flexural strength and microhardness results of the glass-ceramics samples sintered at $700^{\circ} \mathrm{C}, 750^{\circ} \mathrm{C}, 800^{\circ} \mathrm{C}$ and $850^{\circ} \mathrm{C}$ and held for five different periods: $1.0,3.0$, and $6.0,9.0$ and 12.0 hours respectively. The flexural strength values reported in this study were considerably higher than the reported 120-140 MPa values for leucite glass-ceramics currently used in dentistry [11]. Based on the pattern of both graphs (Figure 3 and Figure 4), it were observed that the flexural strength and microhardness were slightly increased as the sintering temperature was increased from $700^{\circ} \mathrm{C}$ to $850^{\circ} \mathrm{C}$ and held for $1.0,3.0,6.0$ and 9.0 hours. This probably due to the existence of mixture of phases in the glass-ceramics that has increased the strength of glass-ceramics. For all sintering temperature it also showed that the 9 hours hold of sintering have the highest values of flexural strength and microhardness. However, the flexural strength and microhardness values were decreased when the sintering was held for more than 9.0 hours. This is probably because prolonged holding led to crystals coalescence and reduction in leucite area fraction.

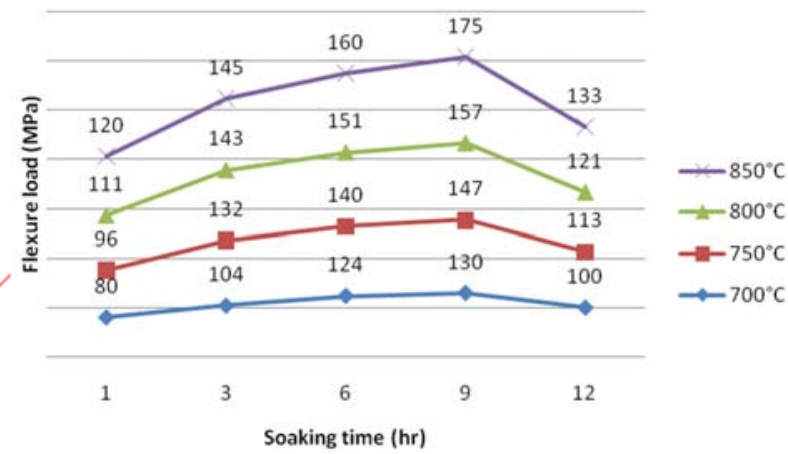

Fig. 3 The flexural strength test results for samples sintered at $700^{\circ} \mathrm{C}, 750^{\circ} \mathrm{C}, 800^{\circ} \mathrm{C}$ and $850^{\circ} \mathrm{C}$

The examined indentation of microhardness of the sintered and polished surfaces of the samples did not show significant differences depending on the number and size of the leucite crystals present in the glass-ceramics, especially for sample that sintered between $700^{\circ} \mathrm{C}$ to $750^{\circ} \mathrm{C}$.

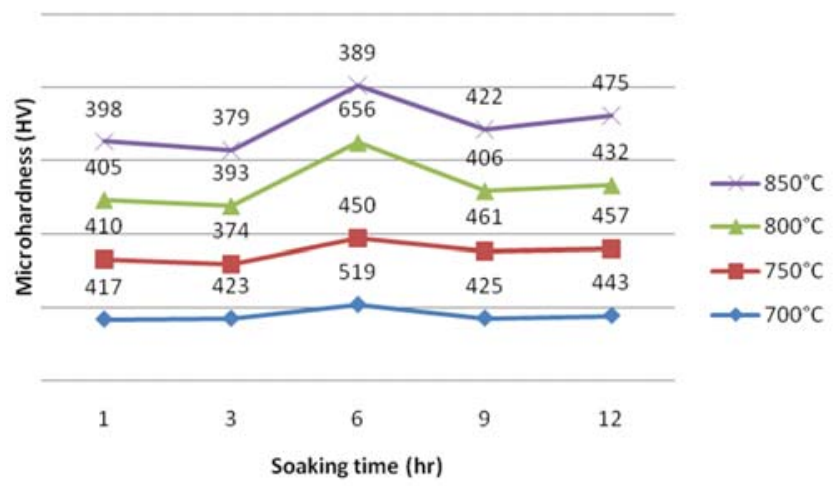

Fig. 4 The microhardness test results for samples sintered at $700^{\circ} \mathrm{C}, 750^{\circ} \mathrm{C}, 800^{\circ} \mathrm{C}$ and $850^{\circ} \mathrm{C}$ 


\section{FESEM Micrographs}

For glass specimens sintered at $850^{\circ} \mathrm{C}$, the cubic structure of leucite is observed to become solid mass and the grain boundaries were also became less. At this stage the glass specimen were fully sintered. Previous research done also observed an early stage of leucite crystal growth where dendritic leucite grew in preferred crystallographic directions

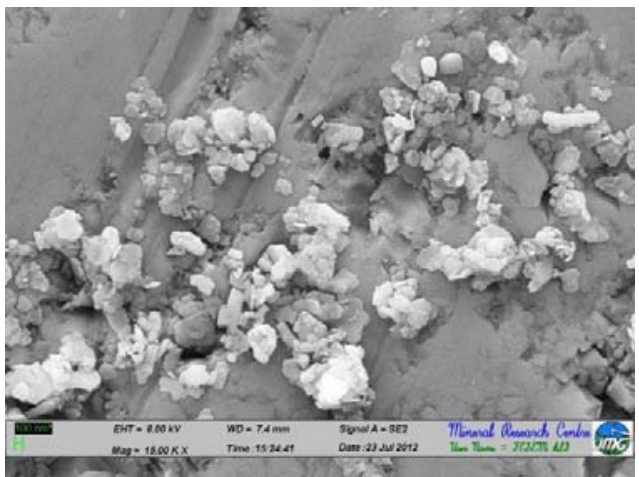

(a)

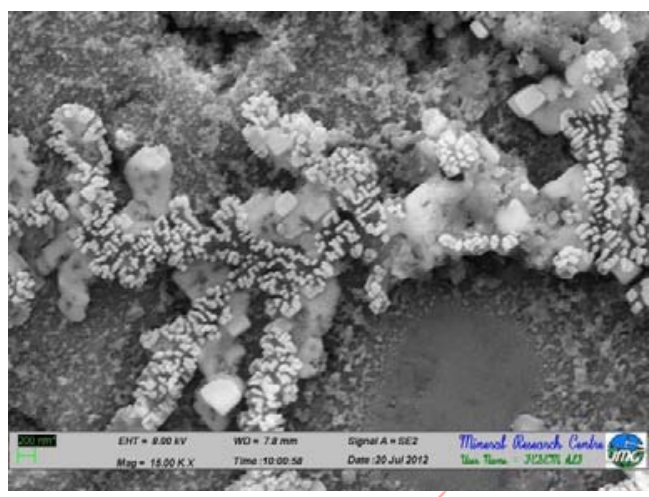

(c) controlled by diffusion [1]. Increased in sintering temperature and prolonged holding, led to crystals coalescence, reduction in leucite area fraction and increase in the mean leucite crystal size as showed in Figure 5. Partial dissolution of leucite crystals was revealed with prolonged heating of leucite glass-ceramics in the range of $800-850^{\circ} \mathrm{C}[3]$.

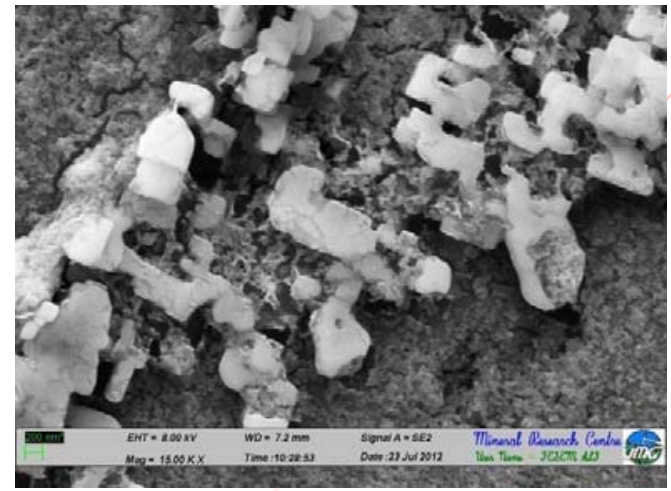

(b)

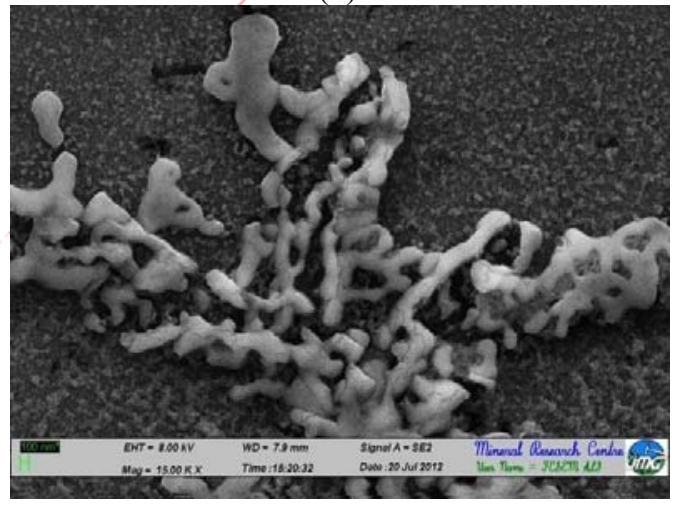

(d)

Fig. 5 FESEM micrographs of glass specimen sintered for 1 hour at (a) $700^{\circ} \mathrm{C}$; (b) $750^{\circ} \mathrm{C}$; (c) $800^{\circ} \mathrm{C}$; (d) $850^{\circ} \mathrm{C}$

\section{CONCLUSION}

Terengganu silica sand deposits can be used as $\mathrm{SiO}_{2}$ source for producing leucite glass-ceramics for dental applications without any further chemical upgrading (in order to improve the purity of the silica sand and remove the impurities) to get rid some of the impurities such as iron and alumina.

The study of the crystallization behaviour of leucite crytals were carried out in order to explore the most favorable crystal growth temperatures and soaking period. Results from the characterization of the glass-ceramics shows that the cubic leucite have crystallized when the glass specimens were sintered at $700^{\circ} \mathrm{C}, 750^{\circ} \mathrm{C}, 800^{\circ} \mathrm{C}$ and $850^{\circ} \mathrm{C}$ for 1.0, 3.0, 6.0, 9.0 and 12.0 hours. The XRD patterns of all samples showed that the phase changes with the increase of temperature and soaking time of sintering. The formation of the cubic leucite is increased with an increase in the sintering temperature. However, prolonged holding of sintering up to 12 hours contributed to the formation of coexistence phases which are sanidine and microcline.

The microhardness and three point bending test results show that the mechanical strength of the samples were increased as the temperatures and sintering times were increased. The FESEM micrographs showed that the crystallization of leucite in bulk glass samples is characterized by the preferred orientation of crystals that grow from the surface.

A processable cubic leucite glass-ceramic with high flexural strength, microhardness and reliability was the output of this research, and may be useful for the application of durable and strong esthetic dental restorations.

\section{ACKNOWLEDGEMENT}

The authors would like to thank Dato' Zulkifly Abu Bakar, Director of Mineral Research Centre Malaysia, Mr. Malek Selamat, Head of Advanced Material Section of 
Mineral Research Centre and all staff of Mineral Research Centre who were involved and had contributed in this research work.

\section{REFERENCES}

[1] M.J.C.T Cattell, J.C. Knowles, R.L. Clarke, Dent. Mater 21 (2005) 811.

[2] C.T. Chen X, R. Wilson, R. Hill, M. Cattell, J Dent Res 89 (2010) 1510.

[3] I. Szabo, B. N., G. Volksch, W. Holand. J Non-Cryst Solids 272 (2000) 191 .

[4] H.H. Lee, K. Asaoka, Dent. Mater 16 (1997) 134.

[5] JR.B.M. Mackert, C.W. Fairhurst. Dent. Mater 2 (1986) 32.
[6] JR.R.C. Mackert, A.L. Evans-Williams, J Dent Res 80 (2001) 1574.

[7] M.J. Cattell, C.J. Knowles, Richard L. Clarke, Dayananda Y.D. Samarawickrama, Dent. Mater 22 (2006) 925.

[8] N.M Bobkova, N. M. K. m., I.A. Bogdanovich, Glass Ceram 65 (2008) 32 .

[9] Weinstein M., K. S., Weinstein AB (1962). Fused porcelain to metal teeth. U.S. 3,052,982

[10] Wolfram Holand, M. F., Volker Rheinberger, J Non-Cryst Solids 180 (1995) 292.

[11] Xiaohui Chen, T. C. C., Rory M. Wilson, Robert G. Hill, Michael J. Cattell, Dent. Mater 27 (2011) 1153. 